\title{
Comunidades de Prática e a formação do professor que ensina Matemática revisitando teses e dissertações
}

Resumo: Neste texto são apresentados resultados de um levantamento feito na Biblioteca Digital Brasileira de Teses e Dissertações (BDTD) de estudos, realizados nos anos de 2008 a 2017, sobre a formação de professores de Matemática em Comunidades de Prática (CoP). O objetivo foi verificar se estas pesquisas envolviam, ou não, investigações sobre ações colaborativas e/ou tratavam das especificidades dos conhecimentos docentes. Os resultados apontam a formação continuada de professores em CoP como uma alternativa aos programas tradicionais fundamentados em cursos de treinamento ou de reciclagem de conhecimentos e indicam $\mathrm{CoP}$ como um cenário no qual a aprendizagem compartilhada, de modo colaborativo e participativo, promove o desenvolvimento profissional dos professores. Observa-se que apesar de os estudos abordarem ou a colaboração ou os conhecimentos docentes na formação do professor, no âmbito das CoP, nenhum deles teve por objetivo investigar inter-relações entre estes dois aspectos teóricos.

Palavras-chave: Formação de Professores. Comunidade de Prática. Ações Colaborativas. Conhecimentos Docentes. Matemática.
Ana Paula Barbosa de

Lima

Doutora em Educação Matemática e Tecnológica. Professora de

Matemática da Educação Básica. Pernambuco, Brasil.

(iD) orcid.org/0000-0003-0301-6449

$\triangle$ lima.apb@gmail.com

Rute Elizabete de Souza Rosa Borba

Doutora em Educação Matemática. Professora do Programa de PósGraduação em Educação Matemática e Tecnológica da Universidade

Federal de Pernambuco (UFPE) Pernambuco, Brasil

(iD) orcid.org/0000-0002-5098-4461

$\bowtie$ resrborba@gmail.com

Recebido em 05/11/2020 Aceito em 09/12/2020

Publicado em 01/01/2021

\section{Communities of Practice and the training of the mathematics teacher: revisiting theses and dissertations}

Abstract: This text presents the results of a survey carried out at the Brazilian Digital Library of Theses and Dissertations (BDTD) of studies performed, in the years 2008 to 2017, on the formation of Mathematics teachers in Communities of Practice (CoP). The objective was to verify if these researches involved, or not, investigations about collaborative actions and/or dealt with the specificities of teacher knowledge. The results point to the continued formation of teachers in $\mathrm{CoP}$ as an alternative to traditional programs based on training courses or knowledge recycling and indicate $\mathrm{CoP}$ as a scenario in which shared learning, in a collaborative and participatory way, promotes the professional development of teachers. It is observed that although the studies address either the collaboration or the knowledge in teacher education, within the scope of the $\mathrm{CoP}$, none of them aimed at investigating interrelations between these two theoretical aspects.

Keywords: Teacher Training. Community of Practice. Collaborative Actions. Teacher Knowledge. Mathematics. 


\section{Comunidades de Práctica y la formación de los profesores que enseña Matemáticas: revisando tesis y disertaciones}

Resumen: Este texto presenta los resultados de un levantamiento hecho en la Biblioteca Digital Brasileña de Tesis y Disertaciones (BDTD) de estudios, realizada en los años 2008 a 2017, sobre la formación de profesores de Matemática en Comunidades de Práctica $(\mathrm{CoP})$. El objetivo era verificar si estas investigaciones involucrados, o no, las investigaciones acerca de las acciones de colaboración y/o negociados con las características específicas de los conocimientos de enseñanza. Los resultados apuntan a la formación continuada de docentes en CoP como alternativa a los programas tradicionales basados en cursos de formación o reciclaje de conocimientos e indican a $\mathrm{CoP}$ como un escenario en et que el aprendizaje compartido, de forma colaborativa y participativa, promueve el desarrollo profesional de los docentes. Se observa que si bien los estudios abordan la colaboración o el conocimiento docente en la formación docente, en el contexto de la CoP, ninguno de ellos tuvo como objetivo investigar las interrelaciones entre estos dos aspectos teóricos.

Palabras clave: Formación del Profesorado. Comunidad de Práctica. Acciones Colaborativas. Conocimiento de Enseñanza. Matemáticas.

\section{Introdução}

Neste artigo são apresentados e discutidos os dados de um levantamento feito a partir da análise de teses e dissertações brasileiras, defendidas entre os anos de 2008 e 2017, com foco na formação do professor que ensina Matemática e que tinham como fundamento teórico o conceito de Comunidade de Prática (Community of Practice CoP). O objetivo foi verificar se estas pesquisas envolviam, ou não, investigações sobre ações colaborativas e/ou trataram das especificidades de conhecimentos docentes. Ambas as temáticas foram foco do estudo de doutorado desenvolvido pela primeira autora e supervisionado pela coautora deste trabalho, com tese defendida em 2019․ Daí o interesse no levantamento de estudos anteriores com um foco, com outro foco, ou interrelacionando ambos.

Estudo semelhante foi desenvolvido por Ramos (2015), a partir de pesquisas indexadas no banco de teses e dissertações da Coordenação de Aperfeiçoamento de Pessoal de Nível Superior (CAPES). A partir dos descritores de busca 'formação de professores, Comunidade de Prática e Matemática', a autora identificou apenas sete trabalhos, publicados nos anos de 2011 e 2012, do quais apenas dois usavam o conceito

\footnotetext{
${ }^{1}$ Com a tese defendida em 2019, o levantamento apresenta os dados de um período de 10 anos (2008-2017) anterior à finalização da pesquisa.
} 
de Comunidade de Prática como aporte teórico para o desenvolvimento de estudos sobre a formação do professor de Matemática. Ressalta-se que o estudo de Ramos (2015) e os analisados em sua revisão - Beline (2011) e Oliveira (2012) - fazem parte da composição do corpo de análise do presente estudo.

No levantamento realizado por Rodrigues, Silva e Miskulin (2017) foram identificadas 46 pesquisas, a partir de teses e dissertações defendidas entre os anos de 2005 e 2016 e indexadas no sistema da Biblioteca Digital de Teses e Dissertações (BDTD) e nas bibliotecas digitais de Programas de Pós-Graduação em Educação, Educação Matemática ou de Ensino de Ciências e Matemática. O estudo teve como objetivo compreender o desenvolvimento conceitual do que é uma Comunidade de Prática e identificar os reflexos dessa teoria em pesquisas no campo da Educação Matemática no Brasil. No levantamento foram utilizados como descritores de busca os termos "Comunidades de Prática" e "Wenger".

Já o levantamento feito por Tinti e Manrique (2017) teve como objetivo quantificar projetos sobre aprendizagem docente desenvolvidos no âmbito do Programa Observatório da Educação (Obeduc) na perspectiva de Comunidades de Prática. A busca, realizada no site da CAPES, identificou 40 projetos Obeduc, dos quais dois abordavam aspectos específicos de CoP. A partir desses dois projetos, os autores fizeram o mapeamento das pesquisas desenvolvidas e analisaram, ao todo, seis produções, entre teses e dissertações resultantes desses projetos. Vale ressaltar que os estudos analisados por Tinti e Manrique (2017) fazem parte do corpo de estudos apresentados no presente artigo, quais sejam, Rocha (2013), Garcia (2014), Oliveira (2014), Ramos (2015), Barros (2016) e Tinti (2016).

Em uma rápida análise quantitativa dos estudos de Ramos (2015), Rodrigues, Silva e Miskulin (2017) e Tinti e Manrique (2017) observa-se um aumento considerável na identificação de estudos que tiveram como base teórica o conceito de Comunidades de Prática. Talvez os poucos estudos apresentados por Ramos (2015) se deva ao fato de uma não atualização dos dados do banco de teses e dissertações da CAPES na época do levantamento efetuado pela autora.

Neste artigo serão apresentadas análises de estudos desenvolvidos em Comunidades de Prática (CoP) presenciais, ao passo que os estudos de Ramos (2015) e 
Rodrigues, Silva e Miskulin (2017) incluíram também atividades em ambientes virtuais, com ou sem encontros presenciais, ou, ainda, atividades em sala de aula, tendo os alunos da turma como membros dessas CoP. Já o estudo de Tinti e Manrique (2017) se restringiu a comunidades desenvolvidas no âmbito do Obeduc.

\section{Formação de Professores que Ensinam Matemática}

Nos últimos anos a área educacional brasileira vem passando por novas mudanças curriculares, que impactam direta e indiretamente na formação inicial e/ou continuada dos professores. As principais mudanças foram a aprovação de uma Base Nacional Comum Curricular (BNCC) para a Educação Básica (BRASIL, 2018a) e alterações nos editais do Programa Nacional do Livro Didático (PNLD), que é o programa responsável por avaliar e distribuir livros didáticos para toda a rede pública de ensino, para que os novos livros estejam de acordo com as novas políticas educacionais sugeridas pela BNCC. Esses dois programas governamentais têm influenciado diretamente nas expectativas do que se almeja ser realizado em salas de aula do ensino básico e, indiretamente, naquilo que se espera tratar na formação de professores.

Além dessas mudanças, desde o ano de 2018 vem sendo discutido, no Conselho Nacional de Educação (CNE), a criação de uma Base Nacional Comum (BNC) para Formação do Professor da Educação Básica. Em sua versão preliminar (BRASIL, 2018b), o documento propõe mudanças para os cursos de Licenciatura (Pedagogia e especialidades diversas), apresentando 10 diretrizes para a formação dos professores, tais como a aplicação anual e obrigatória aos concluintes dos cursos de Licenciatura, do Exame Nacional de Desempenho de Estudantes (ENADE), por entender que esta é uma forma de habilitação para a atividade docente; a substituição do estágio supervisionado por um programa de residência pedagógica; e um estágio probatório para recémformados.

Assim, a proposta da BNC (BRASIL, 2018b) para a formação de professores é de que esta tenha como foco a prática profissional desde o início dos cursos de licenciaturas. Dessa forma, os futuros professores terão atividades docentes em uma escola ao menos uma vez por semana, ao longo de toda a sua graduação. Ainda segundo o documento preliminar da BNC da Formação de Professores (BRASIL, 2018b, p. 43) "não basta que 
o professor tenha o saber conceitual ou a capacidade transmissiva, ele precisa desenvolver o domínio relacional, a habilidade de conviver na diversidade das situações de sala de aula e estar comprometido com o seu fazer profissional". O documento destaca, ainda, três dimensões para o desenvolvimento da competência profissional, são elas: i) conhecimento profissional, associado com a prática docente adquirida por meio de experiências em sala de aula; ii) prática profissional, por intermédio da associação entre a aprendizagem dos conteúdos específicos e a aprendizagem de metodologias de ensino e avaliação; e iii) engajamento profissional, que pode ser considerado como conceito que estrutura a atividade docente e implica no compromisso do professor, como profissional, com seus alunos, com colegas de profissão, com a comunidade em que atua e com a sociedade de modo mais amplo.

Essa proposta da BNC vem ao encontro do que pesquisas vêm mostrando, ao longo dos anos, como os modelos de formação de professores, em especial dos professores que ensinam Matemática, impactam na formação deles. Segundo Ramos (2015, p. 15), é preciso levar em consideração as deficiências e lacunas que são identificadas em cursos de formação de professores, assim "é fundamental o incentivo, por parte de políticas públicas, a iniciativas que busquem complementar a formação inicial e propor ações voltadas para a formação continuada e o desenvolvimento profissional dos professores". Isso com o objetivo de melhorar a prática do professor a partir de reflexões quanto as suas atividades docentes.

Sobre esses modelos de formação de professores de Matemática no Brasil, Fiorentini et al. (2002) mostram que nas décadas de 1970 e 1980 os programas de formação continuada tinham como fundamento propor cursos de reciclagem ou treinamentos com a finalidade de atualizar o professor quanto a técnicas de ensino. Este tipo de formação, segundo as Referências de Formação para Professores (BRASIL, 1999, p. 41), "não respondem às necessidades pedagógicas mais imediatas dos professores e nem sempre se constituem num programa articulado e planejado como tal". Já nos anos 1990, a tendência, segundo Fiorentini e Crecci (2017, p. 182), foi de pesquisas para e sobre os professores que ensinam Matemática e, só a partir dos anos 2000, é que surgiram estudos com professores, "estabelecendo parcerias ou grupos colaborativos de estudo conjunto entre universidade e escola ou entre formadores/pesquisadores e professores escolares". 
A partir de um levantamento da pesquisa acadêmica brasileira, entre os anos de 2001 e 2012 (FIORENTINI, PASSOS e LIMA, 2016) sobre a formação do professor que ensina Matemática, Fiorentini e Crecci (2017) apontam que mais de 80\% dos estudos analisados no período tratavam de contextos formativos por meio de um trabalho conjunto ou colaborativo entre escolas e universidade. Outro destaque é que as formações continuadas, nesse período, envolviam, na maior parte do tempo, os professores das escolas em processos interventivos intercalados entre momentos de reflexão e investigação de suas próprias práticas.

Apesar da ampliação e modificação nas temáticas voltadas à formação de professores e ao seu desenvolvimento profissional, Fiorentini e Crecci (2017, p. 181), chamam a atenção de que ainda há muito a se investigar sobre a "natureza e a especificidade dos saberes e conhecimentos profissionais", de preferência nas investigações pautadas na formação inicial e continuada de professores que ensinam Matemática em contextos da prática docente. Ponte (1998) ressalta que, para favorecer ao desenvolvimento profissional, é importante que os professores estejam inseridos em contextos colaborativos - formados por intermédio da universidade ou construídos voluntariamente entre os professores da escola - de modo que possam interagir com os demais colegas, trocando experiências e compartilhando materiais.

Para Estevam e Cyrino (2016), a proposição de espaços colaborativos pode desencadear ações de formação e realização de pesquisas em Comunidades de Prática. Em consonância a essa perspectiva, "os professores aprendem quando geram conhecimento local da prática, trabalhando nos contextos das comunidades de investigação para teorizar e construir seu trabalho e conectá-lo a questões sociais, culturais e políticas mais amplas" (COCHRAN-SMITH e LYTLE, 1999, p. 250), favorecendo, dessa forma, o desenvolvimento profissional dos professores. Cyrino (2013) afirma, ainda, que as Comunidades de Prática vêm ganhando notoriedade na pesquisa científica sobre o professor que ensina Matemática como um espaço no qual é possível explorar os processos de formação inicial e continuada de professores.

Daí surgiu a proposta do presente levantamento, considerando investigações sobre ações colaborativas em Comunidades de Prática escolares e/ou que trataram de especificidades dos conhecimentos docentes. Para isso, fez-se busca de pesquisas, de 
mestrado e doutorado, que desenvolveram suas investigações sobre a formação do professor que ensina Matemática no âmbito de Comunidades de Prática.

\section{Comunidades de Prática}

Wenger, McDermott e Snyder, (2000) definem Comunidade de Prática (CoP) como sendo um grupo de pessoas que compartilham uma preocupação, de um conjunto de problemas ou paixão por algo que fazem, de modo que haja uma interação regular entre eles. Essa interação deve ter com o propósito desenvolver e consolidar os conhecimentos e as experiências do grupo para que possam resolver os problemas que surgem e fazer o que gostam ficar cada vez melhor. Segundo Wenger (1998, p. 6), "comunidades de prática estão em toda parte" — nas escolas, no trabalho, nos nossos hobbies - e podemos pertencer a várias delas. Além disso, o autor afirma que essas CoP se modificam ao longo do tempo e de acordo com os interesses de cada pessoa a elas pertencentes.

Uma Comunidade de Prática apresenta três elementos fundamentais para sua constituição, como representado na Figura 1. Segundo Wenger, McDermott e Snyder (2002, p. 27), os elementos fundamentais de uma CoP são: “um domínio do conhecimento, que define um conjunto de questões; uma comunidade de pessoas que se preocupam com esse domínio; e a prática compartilhada que elas estão desenvolvendo para serem eficazes em seus domínios".

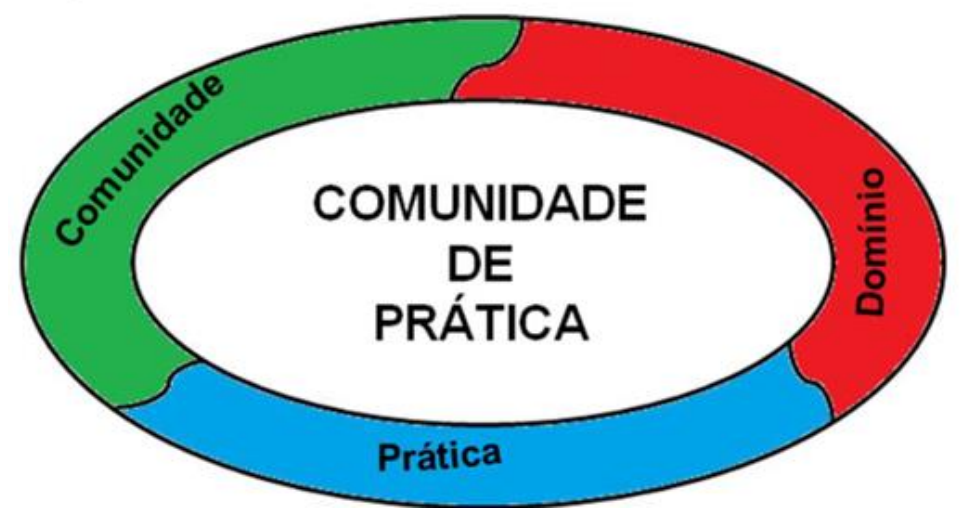

Figura 1: Elementos constituintes de uma Comunidade de Prática (LIMA, 2019, p. 64)

Estes três elementos, quando tomados em conjunto, fazem da CoP uma "estrutura de conhecimento ideal — uma estrutura social que pode assumir a responsabilidade pelo 
desenvolvimento e compartilhamento de conhecimento" (WENGER, McDERMOTT e SNYDER, 2002, p. 27). Sendo assim, cada um destes elementos - domínio, comunidade e prática - contribui com a $\mathrm{CoP}$ de modo a permitir a existência da capacidade de administrar o conhecimento desenvolvido entre seus membros.

Porém, Wenger (1998) chama a atenção de que nem toda comunidade ou prática podem ser característicos das definiçõoes usadas para designar uma CoP. Por exemplo, um bairro residencial que, em algumas localidades é chamado de comunidade, não se caracteriza como um elemento de uma $\mathrm{CoP}$, pois pode não apresentar elementos que façam referência à aprendizagem de seus membros, a partir de respeito mútuo e da interação entre seus membros. Pois, como afirmam Wenger, McDermott e Snyder (2002, p. 28), "a comunidade é um elemento importante porque o aprendizado é uma questão de pertença, bem como um processo intelectual, que envolve o coração e a cabeça". No mesmo sentido, para ser um bom violonista é preciso muito prática, mas essa prática pode ser apenas para crescimento individual, não caracterizando, assim o que Wenger, McDermott e Snyder (2002) definem como prática de uma CoP, que se caracteriza como o conhecimento específico desenvolvido, compartilhado e mantido pela comunidade, além de a distinguir de outros significados como a cultura, atividade ou estrutura.

Assim, Wenger (1998) defende que a associação entre os conceitos de comunidade e prática contribuem para a definição e para o funcionamento de uma CoP. E é a partir da associação entre estes dois elementos que surgem três dimensões que irão definir as ações desenvolvidas na $\mathrm{CoP}$, são elas: o engajamento mútuo (mutual engagement), o empreendimento articulado (joint enterprise) e repertório compartilhado (shared repertoire).

O engajamento mútuo é uma das características que definem a prática de uma $\mathrm{CoP}$ por ser responsável pelo envolvimento recíproco entre os membros e pelo sentimento de pertença a esta CoP quando as ações desempenhadas são negociadas entre os membros. Apesar disso, esse envolvimento e negociação não significa que haja sempre uma relação de homogeneidade, uma vez que podem acontecer situações que sejam conflituosas, desarmônicas ou de competição entre os membros, mas que ainda assim, contribuem para o crescimento da comunidade.

O empreendimento articulado é o resultado do processo de negociação coletiva 
que retrata a complexidade do engajamento mútuo e dá origem às relações de responsabilidade mútua entre os membros da CoP. Além disso, este empreendimento articulado modifica-se de acordo com as necessidades dos membros da $\mathrm{CoP}$, expondo os diferentes pontos de vista destes de forma positiva e produtiva para o empreendimento em questão.

O repertório compartilhado diz respeito ao material que rege e normatiza o funcionamento de uma $\mathrm{CoP}$, ao modo como as atividades são desenvolvidas, pelos discursos e conceitos que são produzidos ou praticados pelos membros da CoP, além das histórias, materiais e experiências compartilhadas entre eles. Para Wenger (1998) todos estes elementos tornam-se parte da prática desenvolvida na CoP.

A seguir é apresentado o percurso metodológico adotado para o levantamento das dissertações e teses. Além disso, são apresentados os critérios para seleção dos estudos que compõe o corpo de análise do presente artigo.

\section{Encaminhamento metodológico}

O objetivo desse levantamento foi identificar, em teses e dissertações, estudos sobre formação de professores que tinham como escopo principal a formação em Comunidades de Prática. Além disso, teve-se como intuito investigar se nestas pesquisas há uma discussão teórica envolvendo investigações sobre ações colaborativas e/ou se tratava das especificidades de conhecimentos docentes.

Os estudos aqui analisados fazem parte do banco de dados da Biblioteca Digital Brasileira de Teses e Dissertações (BDTD). Para a identificação dos textos foram utilizados como descritores de busca os termos Comunidade de Prática e Matemática, do período entre janeiro de 2008 e dezembro de 2017, totalizando, assim, 10 anos de trabalhos publicados na temática deste artigo.

A partir dos descritores de busca foram identificados, ao todo, 33 textos, entre teses e dissertações. Estes textos foram submetidos a uma leitura preliminar, com o objetivo de identificar as pesquisas nas quais os encontros de formação tivessem sido realizados presencialmente, ou seja, sem a realização de encontros virtuais. Embora o foco desse levantamento sejam pesquisas desenvolvidas presencialmente, alguns estudos 
aqui analisados tiveram tarefas disponibilizadas em ambientes Moodle que seriam discutidas nos encontros presencias. Sendo assim, estas pesquisas foram consideradas nesse levantamento. A justificativa dessa escolha tem por princípio o objeto de estudo de nossa pesquisa de doutorado (LIMA, 2019) que investigou se o Colégio de Aplicação da Universidade Federal de Pernambuco (CAp-UFPE) poderia ser considerado uma Comunidade de Prática $(\mathrm{CoP})$ e se havia influências mútuas entre ações colaborativas e o desenvolvimento dos conhecimentos docentes dos professores de Matemática desta instituição.

Após a leitura preliminar, que descartou pesquisas com encontros exclusivamente virtuais ou que não se referiam à formação de professores, 20 trabalhos foram selecionados para leitura completa e análise de seus dados. A seguir são apresentados os dados quantitativos dos respectivos trabalhos e a discussão de cada um deles dentro do campo da formação de professores que ensinam Matemática.

\section{Resultados e discussão}

A análise inicial dos 20 textos mostra a distribuição de teses e dissertações de acordo com o ano de publicação de cada um desses textos, conforme se pode observar no Gráfico 1. Percebe-se, assim, que ao longo do período investigado (2008 a 2017), em quase todos os anos houve um ou mais trabalhos que tinham como foco formações de professores que ensinam Matemática em contextos de Comunidades de Prática no modelo presencial.

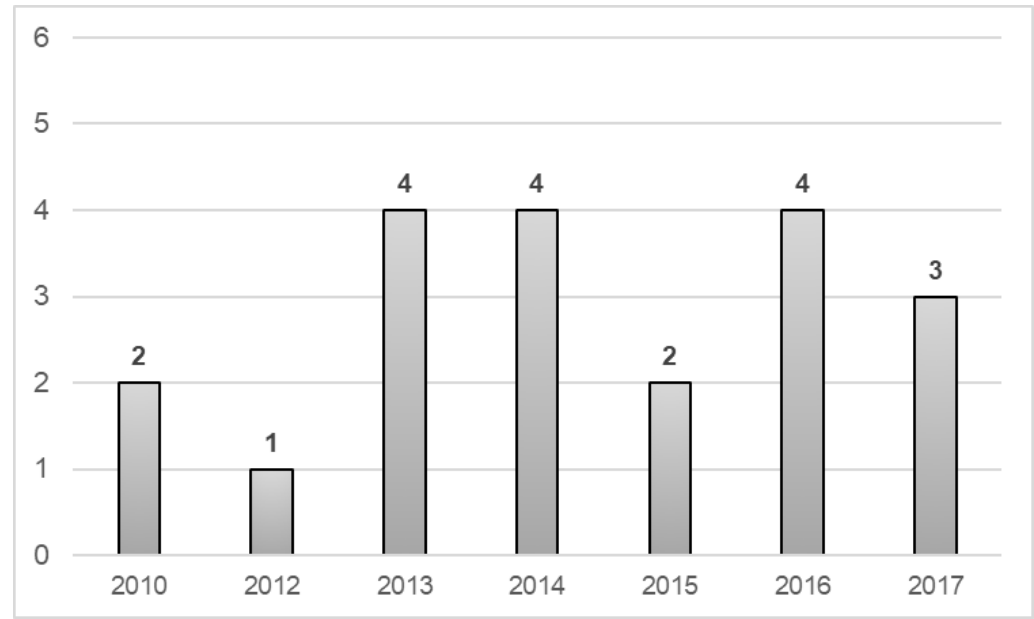

Gráfico 1: Teses e dissertações publicadas entre 2008 e 2017 sobre

Comunidades de Prática presenciais (LIMA, 2019, p. 33) 
Observou-se, também, que as CoP eram constituídas por professores ou futuros professores de diferentes níveis/etapas de ensino - Anos Iniciais ou Finais do Ensino Fundamental, Ensino Médio ou Ensino Superior; estudantes de cursos de licenciatura em Matemática ou Pedagogia; discentes de programas de Pós-graduação (mestrandos ou doutorandos). Assim foi possível classificar os trabalhos em três distintas categorias, definidas de acordo com a formação ofertada aos participantes, como observado no Quadro 1.

Quadro 1: Estudos sobre formação de professores de Matemática no âmbito de Comunidades de Prática

\begin{tabular}{|c|c|c|}
\hline Categoria & Sujeitos & Autores \\
\hline \multirow{2}{*}{$\begin{array}{l}\text { Professores em } \\
\text { formação inicial }\end{array}$} & $\begin{array}{l}\text { Professores e licenciandos em } \\
\text { Matemática ou Pedagogia }\end{array}$ & $\begin{array}{c}\text { Caldeira (2010); Melo (2010); } \\
\text { Menegazzi (2014) }\end{array}$ \\
\hline & $\begin{array}{c}\text { Alunos do Programa } \\
\text { Institucional de Bolsas de } \\
\text { Iniciação à Docência (Pibid) }\end{array}$ & $\begin{array}{c}\text { Benites (2013); Mendes (2013); } \\
\text { Rodrigues (2016) }\end{array}$ \\
\hline \multirow{2}{*}{$\begin{array}{c}\text { Professores em } \\
\text { formação Continuada }\end{array}$} & $\begin{array}{l}\text { Atuantes nos Anos Iniciais do } \\
\text { Ensino Fundamental }\end{array}$ & Nagy (2013); Dick (2017) \\
\hline & $\begin{array}{l}\text { Atuantes nos Anos Finais do } \\
\text { Ensino Fundamental }\end{array}$ & Estevam (2015) \\
\hline \multirow{2}{*}{ Grupo misto } & $\begin{array}{l}\text { Professores de Matemática em } \\
\text { exercício, estudantes de cursos } \\
\text { de Licenciatura em Matemática, } \\
\text { mestrandos e doutorandos }\end{array}$ & Beline (2012); Baldini (2014) \\
\hline & $\begin{array}{l}\text { Membros do Observatório da } \\
\text { Educação (Obeduc) }\end{array}$ & $\begin{array}{c}\text { Rocha (2013); Garcia (2014); } \\
\text { Oliveira (2014); Ramos (2015); } \\
\text { Barros (2016); Boneto (2016); } \\
\text { Tinti (2016); Lacerda (2017); } \\
\text { Silva (2017) }\end{array}$ \\
\hline
\end{tabular}

Fonte: Lima (2019, p. 35)

A partir da análise do percurso metodológico de cada uma dessas pesquisas, percebeu-se que, inicialmente, algumas dessas comunidades foram formadas sem as características de uma CoP com o objetivo de serem, posteriormente, caracterizadas como Comunidades de Prática. Já outras pesquisas foram desenvolvidas em CoP já constituídas, como é o caso dos trabalhos desenvolvidos no âmbito do Programa Observatório da Educação (Obeduc) ou do Programa Institucional de Bolsas de Iniciação à Docência (Pibid). Vale salientar que algumas dessas CoP tiveram intervenção por parte do 
pesquisador, que propôs atividades a serem realizadas pelos demais membros da CoP investigada. Já outras CoP, mesmo não sofrendo intervenção direta do pesquisador, estavam em processo de intervenção por parte de outros membros. A seguir serão discutidos os estudos de cada uma das categorias, de acordo com os participantes de cada grupo.

\subsection{Professores em formação inicial}

No grupo de estudos que investigou professores em formação inicial foi possível identificar dois subgrupos, de acordo com a formação e atuação profissional de seus participantes. As pesquisas apresentadas por Caldeira (2010), Melo (2010) e Menegazzi (2014) foram desenvolvidas em comunidades formadas por professores e discentes da Licenciatura em Matemática e discentes do curso de Pedagogia. Já os estudos desenvolvidos por Benites (2012), Mendes (2013) e Rodrigues (2016), tinham como participantes apenas alunos de cursos de Licenciatura em Matemática e em Pedagogia que estavam envolvidos em projetos do Pibid.

Caldeira (2010) desenvolveu o estudo em uma Comunidade de Prática formada por seis estudantes da Licenciatura em Matemática, um professor recém-formado, professores formadores da Universidade de Londrina (UEL), no Paraná, e pela pesquisadora. Foram analisados os modos como esses participantes se envolveram na articulação e negociação de significados durante a realização de tarefas formativas sobre o pensamento algébrico, que eram propostas pela pesquisadora. Nessas tarefas eram resolvidas situações-problema e, em seguida, os participantes apresentavam suas estratégias de resolução e discutiam sobre o significado de pensamento algébrico.

Os resultados apontam que o repertório compartilhado e os empreendimentos articulados sustentaram o domínio e a prática da comunidade. Além disso, concluiu-se que o contexto da CoP permitiu que algumas formas de participação direcionassem a discussão de aspectos do pensamento algébrico, a partir de negociação de significados na prática, provocando mudanças e constituindo a identidade profissional, principalmente dos participantes em formação inicial.

Melo (2010) investigou as formas de aprendizagem e transformação de práticas e saberes em uma comunidade formada por professores e alunos do curso de Licenciatura 
em Matemática da Universidade Federal do Acre (UFAC). Os objetivos foram descrever e analisar o processo de constituição de saberes docentes em um contexto de mudanças curriculares que estavam sendo sugeridas para a formação de professores da Educação Básica; identificar e analisar as práticas da comunidade - como os discursos, saberes, experiências, modelos, teorias, conflitos, resistências, avanços e recuos - de modo a compreender as origens no contexto institucional ao qual a comunidade estava formada; e compreender como os formadores envolvidos com o processo formativo aprendiam e transformavam suas práticas, especialmente seus discursos e saberes sobre a formação dos futuros professores de Matemática.

Os principais resultados apontam, a partir dos discursos dos participantes, que é possível perceber que o incentivo ao engajamento das práticas docentes por meio do currículo fortalece a construção de ambientes favoráveis à participação dos professores. Ao abordar, metodologicamente, as histórias de vida dos professores foi possível perceber as mesmas como um valioso instrumento de diálogo e aprendizagem entre os participantes da comunidade investigada. Além disso, as histórias de vida se configuraram como um modo de engajamento e participação dos professores. Foram as formas de engajamento, compartilhamento e participação que revelaram aspectos estruturantes da constituição de saberes dos professores.

Menegazzi (2014) investigou as concepções a respeito de frações de oito discentes do curso de Pedagogia da Universidade Luterana do Brasil (ULBRA), campus Guaíba (RS), no intuito de identificar as possibilidades de um trabalho colaborativo na formação inicial, para contribuir com o processo de ressignificação dessas concepções e estimular a produção de estratégias voltadas para o ensino de frações nos Anos Iniciais do Ensino Fundamental. O grupo formado foi caracterizado como um grupo colaborativo e, além dos encontros presenciais, os participantes resolveram algumas atividades, disponibilizadas pela pesquisadora, em um ambiente virtual.

Assim, a dinâmica do grupo foi pautada na confiança e no respeito mútuo, os quais fundamentaram o trabalho desenvolvido. Os resultados do estudo apontam que a participação voluntária dos membros, com o objetivo de desenvolvimento profissional, permitiu a construção e o compartilhamento de experiências que contribuirão com a prática dos futuros professores. Além disso, foi possível identificar entre os participantes, 
diferentes identidades de participação, de compartilhamento de objetivo em comum, de empreendimento mútuo e de tarefas compartilhadas.

O que se percebe nessas pesquisas, é que os contextos de formação de professores de Matemática que envolvem elementos de uma CoP são favoráveis a uma formação mais significativa de futuros professores. Outros estudos, apresentados a seguir, investigaram professores de Matemática em formação inicial que participavam, ou tinham participado, como bolsistas, ou ex-bolsistas, do Programa Institucional de Bolsa de Iniciação à Docência (Pibid). Vale ressaltar que ambos os estudos tiveram um processo de intervenção por parte dos pesquisadores, por meio de cursos de extensão oferecidos aos bolsistas.

Benites (2013) investigou como se manifestam as dimensões de colaboração, participação, reflexão e a ressignificação de conceitos e conhecimentos da prática docente no processo de formação de professores de Matemática no âmbito do Pibid, da Universidade Estadual Paulista (Unesp), campus Rio Claro (SP), e como essas dimensões poderiam emergir entre professores e futuros professores - bolsistas do Pibid. Além da observação de reuniões do Pibid, no qual participavam, além dos integrantes do Pibid, a professora supervisora da escola parceira, a coordenadora do Pibid da Universidade, uma professora colaboradora e a própria pesquisadora, a pesquisadora ministrou um curso de extensão intitulado "As potencialidades didático-pedagógicas do software de Geometria Dinâmica Cabri 3D em uma comunidade de aprendizagem/prática em Matemática" (BENITES, 2013, p. 74).

Os resultados mostram que "a formação do professor, via Projeto Pibid, possui pontos positivos e que, alguns conceitos de formação de professores aproximam-se dos conceitos de CoP, como engajamento mútuo, participação, sociabilidade" (BENITES, 2013, p. 167). Um desses pontos positivos do Pibid se refere ao fato de proporcionar aos futuros professores a participação em experiências metodológicas, tecnológicas e práticas docentes de caráter inovador e interdisciplinar, de modo a buscar a superação de problemas identificados no processo de ensino-aprendizagem, levando em consideração o desempenho da escola em avaliações externas. Além disso, por meio da participação, reflexão, colaboração, ressignificação e da aprendizagem compartilhada - entre professores em exercício e futuros professores - a formação desses-profissionais poderá 
acontecer de modo bem amplo e satisfatório.

Mendes (2013) investigou como ocorre a negociação de significados quando os alunos da Licenciatura em Matemática, bolsistas Pibid, planejam, experimentam, vivenciam e refletem sobre a complexidade do que é ensinar e aprender Matemática, tendo a tecnologia como mediadora entre estas ações. Além dos bolsistas, participaram da pesquisa três supervisoras das escolas na qual os alunos realizavam o estágio Pibid e três professoras do curso de Licenciatura em Matemática da Universidade Federal de Lavras (UFLA).

A coleta de dados se deu por meio de um curso de extensão ministrado presencialmente por Mendes (2013) que disponibilizou, também, algumas atividades na plataforma Moodle. Os principais resultados apontam que, para a negociação de significados - ocorrida quando os participantes experimentavam, vivenciavam e refletiam sobre a complexidade do processo de ensino e aprendizagem da Matemática usando tecnologias - foi possível perceber alguns aspectos de formação de uma CoP, como a participação, as interações, a colaboração, o compromisso mútuo, a ação conjunta e a criação de um repertório compartilhado entre os membros.

Rodrigues (2016) investigou uma CoP formada por estudantes licenciandos e participantes do Pibid/Matemática, da Unesp, campus Rio Claro (SP), coordenadores de área das instituições de ensino e professores supervisores das escolas parceiras do Pibid. Os objetivos foram elencar e compreender as potencialidades didático-pedagógicas deste projeto como um espaço para formação de professores de Matemática no Brasil.

Os principais resultados apontam que o Pibid/Matemática, constituídos por diferentes participantes - coordenadores de área, supervisores e licenciandos — se torna um espaço para a formação dos professores, por meio da aproximação e interação entre a universidade e as escolas participantes. Proporciona, também, uma articulação entre teoria e prática e contribui com o redimensionamento da formação de professores de Matemática no Brasil. Além dos elementos constituintes de uma $\mathrm{CoP}$, a autora observou outras características que podem aproximar-se dos conceitos de uma CoP, como a valorização dos momentos de coletividade entre os participantes durante as discussões e tomadas de decisão; o compartilhamento de responsabilidades entre os coordenadores das universidades e os supervisores das escolas públicas, fazendo com que as aprendizagens 
acontecessem em diversas direções e de forma mútua entre os participantes, rompendo com a ideia de que só um grupo é detentor de conhecimentos. As interações eram regulares e a existência de confiança e cumplicidades entre os participantes da CoP intensificaram o compartilhamento de ideias e experiências, apresentando indícios de um trabalho colaborativo entre eles.

\subsection{Professores em formação continuada}

Os estudos desenvolvidos no contexto da formação continuada de professores tinham seus participantes lecionando em turmas dos Anos Iniciais ou dos Anos Finais do Ensino Fundamental. Nagy (2013) investigou uma comunidade de professores que atuavam em turmas dos Anos Iniciais. A comunidade investigada por Dick (2017) era formada por professores que lecionavam Matemática em turmas dos Anos Iniciais e dos Anos Finais do Ensino Fundamental. Já o estudo de Estevam (2015) investigou uma comunidade formada por professores que lecionavam em turmas dos Anos Finais do Ensino Fundamental.

Nagy (2013) investigou que elementos do contexto de uma CoP, formada por nove professoras que ensinam Matemática nos Anos Iniciais do Ensino Fundamental, permitem o desenvolvimento de aprendizagens relacionadas ao conhecimento profissional. Os objetivos foram descrever e analisar como algumas dessas aprendizagens emergiam de empreendimentos dessa CoP por meio de tarefas de resolução e análise de situações-problema e discussão de textos propostos.

Os resultados apontam que a resolução e discussão das tarefas e os relatos e análise do desenvolvimento das tarefas permitiram a aprendizagem das professoras quando se deu a oportunidade para que pudessem expor ou explicar suas resoluções. Além disso, as participantes puderam relatar/partilhar momentos do encontro anterior para as participantes que não estavam presentes, possibilitando a oportunidade para que pudessem compartilhar suas experiências com os trabalhos desenvolvidos em sala de aula. A autora entende que estes resultados são devido à presença de fatores como respeito, confiança, desafio e solidariedade, dentro do contexto da $\mathrm{CoP}$ e que estes elementos relativos a relações pessoais são importantes para o desenvolvimento profissional das professoras. Isso foi possível devido à proposição de um ambiente 
favorável ao compartilhamento de informações que permitiu interações a partir de questionamentos feitos pela formadora.

Dick (2017) investigou como professores, que atuam em turmas dos Anos Iniciais e Anos Finais do Ensino Fundamental, se envolvem com situações em que são propostas atividades experimentais como recursos para o ensino de Matemática, Física e Química e como eles percebem o uso desses recursos em sala de aula. As atividades experimentais realizadas tinham como ponto de partida a leitura e discussão de artigos científicos sobre as temáticas dos encontros e seguiam-se da realização de experimentos que poderiam ser trabalhados nas salas de aula dos professores participantes. Também tiveram momentos de resolução, seguidas de apresentação e discussão das resoluções feitas pelos membros da comunidade.

Os principais resultados apontam que este tipo de formação, com um grupo constituído como uma CoP, foi capaz de incentivar o uso de atividades experimentais em sala de aula, fez com que os membros conhecessem espaços e recursos disponíveis na escola e foi um meio de desmistificar o ensino de disciplinas do campo das Ciências Exatas. Percebeu-se, também, a manifestação, por parte dos professores, de preocupações e dificuldades em comum na busca de soluções para os desafios de sala de aula.

Estevam (2015) investigou como os empreendimentos articulados, desenvolvidos em uma CoP formada por professores dos Anos Finais do Ensino Fundamental, podem oferecer oportunidades de desenvolvimento profissional no campo da Educação Estatística. Durante oito encontros, o formador propôs tarefas aos demais membros e estes, por sua vez, organizavam-se em duplas ou trios para discutirem e resolverem as situações propostas e, após a resolução, era solicitado que eles pensassem e analisassem características e adequações dos enunciados para serem aplicados em turmas do ensino regular, bem como possíveis estratégias e dificuldades enfrentadas pelos alunos e, ao final, socializavam com o grupo maior as ideias e reflexões feitas entre a dupla ou trio.

Os principais resultados apontam que um conjunto de elementos emergentes na prática de uma CoP oferecem condições de aprendizagem profissional para os membros dessa comunidade. Esses elementos, segundo Estevam (2015), são: i) itinerância de engajamento, relacionada a mudanças no processo de constituição da $\mathrm{CoP}$ e nos diferentes tipos de participação de seus membros; ii) compartilhamento de repertórios; iii) 
compromisso solidário; iv) dinâmicas do(a) grupo/comunidade; v) reflexões compartilhadas e sustentadas; vi) relações de confiança e respeito; vii) espaços de vulnerabilidade e agência mediada, que podem permitir que os professores, ou futuros professores, reconheçam seus erros e limitações e lidem com os conflitos decorrentes da prática docente; e viii) dinamicidade do expert e papel do(s) formador(es). O autor afirma, também, que o desenvolvimento profissional, não têm por base apenas a discussão do empreendimento — problemática estudada — em si, mas resulta da articulação dos elementos mencionados, que se ampliam na prática cotidiana do professor e tornam-se condicionantes para a aprendizagem, a formação continuada e o desenvolvimento profissional de professores.

\subsection{Grupos mistos}

Os estudos apresentados nesta seção estão subdivididos em dois grupos. No primeiro grupo os estudos de Beline (2012) e Baldini (2014) investigaram CoP formadas por professores em exercício na Educação Básica, discentes e professores vinculados a Instituições de Ensino Superior. No segundo grupo, os estudos de Rocha (2013), Garcia (2014), Oliveira (2014), Ramos (2015), Barros (2016), Boneto (2016), Tinti (2016), Lacerda (2017) e Silva (2017) investigaram professores em formação inicial e continuada de professores, no âmbito do programa Observatório da Educação (Obeduc) em três instituições de Ensino Superior brasileiras.

Beline (2012) investigou em que medida a dinâmica assumida na prática de uma CoP permitiu a seus membros desenvolver uma identidade de professores de Matemática. Os objetivos eram apresentar os traços de identidade evidenciados por duas professoras e elencar os elementos que permitiram o desenvolvimento dessa identidade. A dinâmica de trabalho na comunidade era de constituição de pequenos grupos para resolução e discussão de situações-problema, por elaboração de novas situações-problemas, aplicação destes com os alunos dos participantes da comunidade e discussão sobre como se deu o desenvolvimento dessas aulas.

Os principais resultados apontam que a dinâmica dos encontros permitiu uma aproximação entre a universidade e as escolas da Educação Básica, uma vez que as reuniões ocorriam em umas das escolas dos membros da CoP investigada. Outro ponto 
destacado é sobre o olhar para as identidades desenvolvidas pelos participantes que podem permitir a compreensão da complexidade do processo de formação e de percepção sobre o como se aprende ao invés do que se aprende nesses contextos formativos. Além disso, Beline (2012) entende que esses contextos são relevantes para o processo de formação continuada dos professores que nelas estão inseridos.

Baldini (2014) reuniu um grupo de professores interessados em aprender a utilizar o software GeoGebra no ensino de Matemática. Os encontros da comunidade ocorreram nas dependências de uma escola da rede estadual do Paraná que cedeu o laboratório de informática para o desenvolvimento do curso. O objetivo era identificar que elementos da prática, durante a utilização do software, permitem a aprendizagem, o desenvolvimento profissional e os Conhecimentos Tecnológicos e Pedagógicos dos membros da comunidade. Além dos encontros presenciais, a autora disponibilizou um fórum em um ambiente virtual para que os participantes pudessem socializar ideias e interagir com os colegas.

Os principais resultados apontam que as aprendizagens não se limitaram aos conhecimentos do conteúdo trabalhado nas tarefas propostas, nem apenas ao uso do software ou de aspectos pedagógicos, mas, sim, desses elementos em conjunto para o ensino e aprendizagem da Matemática por meio da utilização das tecnologias digitais. $\mathrm{O}$ engajamento entre os membros, ao negociar tarefas e partilhar repertórios, revelam a existência de conhecimentos específicos para utilizar as Tecnologias da Informação e Comunicação (TIC) atreladas ao ensino da Matemática. Este é um domínio do conhecimento profissional do professor que pode influenciar a forma como ocorre a integração de tecnologias na prática pedagógica

Os estudos de Rocha (2013), Oliveira (2014) e Garcia (2014) foram desenvolvidos no âmbito do Obeduc da Universidade Estadual de Londrina (UEL), aprovado pelo Edital 038/2010. Os autores investigaram a Comunidade de Prática formada por seis professoras dos Anos Finais do Ensino Fundamental, um aluno da Licenciatura e uma professora recém-formada, além dos pesquisadores - que desenvolviam seus estudos de mestrado (ROCHA, 2013 e OLIVEIRA, 2014) e doutorado (GARCIA, 2014).

Rocha (2013) investigou os elementos do contexto dessa CoP para saber se eles permitem a aprendizagem de seus membros quando estes buscam aprender e ensinar o 
conteúdo de frações. Garcia (2014) investigou como os elementos da prática promoviam o desenvolvimento da identidade profissional de seus membros. Já Oliveira (2014) investigou como os elementos da prática dessa $\mathrm{CoP}$ oportunizaram aprendizagens relacionadas ao conhecimento matemático de professores sobre raciocínio proporcional, a partir da resolução, discussão e reflexão de situações-problema envolvendo proporção/proporcionalidade. Dessa forma, Oliveira (2014) poderia destacar a importância do conhecimento deste conteúdo matemático a ser ensinado nas escolas como parte do corpo de conhecimentos profissionais do professor.

Os principais resultados obtidos por Rocha (2013) apontam que o processo de negociação de significados e interação, ocorrido durante as discussões sobre o desenvolvimento do conteúdo de frações, mostrou que os membros da comunidade desenvolveram conhecimentos profissionais, tais como os conhecimentos sobre a Matemática e seu ensino. Dessa forma, foi possível identificar que os elementos do contexto da $\mathrm{CoP}$ que evidenciaram a aprendizagem foram: a reflexão sobre a prática, a aplicação dos materiais produzidos e compartilhados entre os membros e desafios em sala de aula.

As análises desenvolvidas por Garcia (2014) evidenciam que os elementos da prática da comunidade, que favorecem a aprendizagem e o desenvolvimento de uma identidade profissional entre seus membros, são i) um plano de trabalho aberto, flexível e minimalista; ii) a existência de autonomia dos membros para escolher o que, e como aprender, sem que haja uma centralidade de poder de decisão, podendo, assim, dar espaço para discussões e compartilhamento de experiências; iii) os momentos de negociação de como será a dinâmica e ações que serão desenvolvidas no grupo; iv) a importância de um vínculo institucional com a universidade, com participação de pesquisadores e formadores, também como membros da comunidade, além de apoio financeiro; v) intercâmbio com membros de outras comunidades; e vi) interação, integração e confronto de diferentes ideias e saberes.

Os resultados do estudo de Oliveira (2014) apontam que a partir das ações de resolução de situações-problema e a discussão reflexiva, com o apoio da literatura, foi possível identificar elementos como: o compartilhamento e a discussão de produções; o estudo e a reflexão a respeito da produção oral e escrita, a partir dos problemas resolvidos; 
e a oportunidade de aprendizagens de seus membros. A autora afirma que o processo de formação continuada, quando estruturado com o intuito de promover o desenvolvimento profissional dos professores, é uma alternativa às propostas tradicionais de formação de professores, uma vez que há uma (res)significação do conhecimento do conteúdo a ser ensinado quando são oportunizadas aprendizagens por meio das interações entre os membros, alicerçadas no respeito, confiança e compromisso destes.

O estudo de Silva (2017) foi desenvolvido no âmbito do Obeduc da Universidade Federal da Bahia (UFBA), aprovado pelo Edital 038/2010. Os objetivos foram analisar as relações de poder na negociação de significados; identificar e analisar a construção da identidade dos membros dessa $\mathrm{CoP}$ e analisar as oportunidades de aprendizagem viabilizadas no contexto da comunidade. A comunidade era formada por pesquisadores e/ou formadores, futuros professores e professores que ensinam Matemática que, durante as reuniões, elaboravam materiais curriculares educativos sobre Matemática com o intuito de auxiliar a aprendizagem de professores e estudantes da Educação Básica.

Os resultados apontam que as relações de poder nas negociações de significados — entre discursos acadêmicos, não acadêmicos, intradisciplinares e interdisciplinares ocorreram quando os membros negociavam significados voltados ao ensino e à aprendizagem sobre operações com números inteiros e grandezas direta e inversamente proporcionais. As análises sugerem, ainda, que as identidades, que foram sendo construídas durante os encontros, conduziam as diferentes afiliações, categorizadas como "identidade como multiafiliação, identidade como imaginação e identidade como engajamento ou compromisso mútuo" (SILVA, 2017, p. 125). Além disso, as oportunidades de aprendizagem dos membros foram possíveis quando surgiam como consequência das características da $\mathrm{CoP}$, das relações e práticas sociais e das diferentes experiências de cada um dos membros da CoP OEM-BA.

No projeto Obeduc da Pontifícia Universidade Católica de São Paulo (PUC-SP), aprovado pelo Edital n ${ }^{\circ}$ 049/2012, os estudos desenvolvidos foram os de Ramos (2015), Barros (2016), Boneto (2016), Tinti (2016) e Lacerda (2017). A comunidade era formada por três professores dos Anos Iniciais, três professores de Matemática dos Anos Finais do Ensino Fundamental, três alunos de graduação do curso de Licenciatura em Matemática e três do curso de Pedagogia, além de discentes das turmas de mestrado e do 
doutorado do programa de Pós-Graduação em Educação Matemática da PUC-SP.

Ramos (2015) teve como objetivo identificar quais eram as negociações de significado sobre a metodologia de resolução de problemas que ocorriam nessa comunidade. Para isso analisou os dados obtidos a partir de observações dos encontros destes professores, em que eles foram provocados a negociarem sobre que temática gostariam de estudar. O tema escolhido foi a metodologia de resolução de problemas e, dessa forma, apresentaram e discutiram pesquisas sobre a temática, elaboraram situaçõesproblema envolvendo o conceito de frações e estas foram resolvidas e discutidas em um dos encontros.

Os resultados apontam que esses momentos de negociação e renegociação de significados sobre a metodologia de resolução de problemas passaram a fazer parte do repertório partilhado entre esses membros. Destaca-se, ainda, o fato de que os membros em processo de formação, discentes da licenciatura em Matemática e Pedagogia, ficaram mais no campo da observação durante as atividades em conjunto com membros mais experientes, professores dos Anos Iniciais e Anos Finais do Ensino Fundamental, enquanto estes tiveram uma participação mais ativa durante as atividades.

Barros (2016) investigou como acontece o movimento de produção de textos e que contribuições pode-se propiciar à formação de professores de Matemática, participantes da comunidade Obeduc. Os dados foram coletados quando os participantes estavam preparando suas produções escritas para serem submetidas a avaliações em eventos científicos, bem como na análise dos pareceres emitidos pelas comissões organizadoras destes.

Os resultados apontam que o apoio dos demais membros da comunidade no momento de escrita e da estruturação de cada texto, contribuiu para a formação continuada dos participantes, bem como possibilitou, aos mesmos, segurança no momento de apresentação de trabalhos em eventos exteriores ao grupo. É essa apresentação que, segundo a autora, pode proporcionar um engajamento profissional do grupo. Outro aspecto apontado diz respeito à importância da reflexão coletiva sobre a prática da escrita, que permite ao professor uma ampliação do olhar para as questões da Matemática. Sendo assim, a autora considera que houve um crescimento profissional dos membros da comunidade, o que valida a produção escrita como um meio para a formação 
do professor que ensina Matemática.

Boneto (2016) buscou identificar indícios de representações sociais dos membros sobre o grupo enquanto espaço de formação continuada. Assim, a autora pretendia responder à questão se era possível perceber alterações na fala coletiva do grupo ao longo dos encontros e que alterações seriam estas. Para isso, foi feita uma análise do discurso, a partir da gravação de áudio das reuniões, além de registros escritos (narrativas e memoriais elaborados pelos participantes) realizados ao fim de cada encontro.

Os resultados apontam para a existência de indícios de representações sociais acerca da CoP como um espaço de formação continuada e que estes indícios foram se alterando ao longo dos encontros. A participação mútua dos membros da comunidade para a construção de um ambiente que valorizasse e respeitasse a expressão de afetividade dos membros - mesmo que, em algumas vezes, houvesse tensões e conflitos de ideias legitimaram esses indícios de que os membros consideram o grupo como um espaço de formação continuada.

Tinti (2016) desenvolveu seu estudo com os objetivos de identificar e descrever algumas das aprendizagens docentes evidenciadas no contexto da CoP Obeduc e analisar e discutir como o contexto de desenvolvimento dessa CoP permite tais aprendizagens. Para a coleta de dados foram consideradas as gravações em áudio dos encontros ocorridos entre os anos de 2013 e 2015.

Os principais resultados apontam que, dentre as aprendizagens evidenciadas durante os encontros, há um destaque para a escrita e reflexão sobre a própria prática, a elaboração de atividades na perspectiva da metodologia de resolução de problemas, além do estudo e manuseio de materiais manipuláveis para o trabalho com frações em turmas da Educação Básica. Além disso, com a diversidade de perfis e experiências dos membros, percebeu-se evidências de construção e pertencimento à CoP Obeduc e elas foram importantes elementos do contexto que permitiu o desenvolvimento dessas aprendizagens.

Lacerda (2017) observou três estudantes do curso de Pedagogia, com o objetivo de identificar a contribuição que a participação nessa CoP traria para a formação inicial desses estudantes. A análise se deu a partir de uma tarefa em que os participantes tinham que planejar e aplicar uma atividade em conjunto com os professores dos Anos Iniciais - 
que também eram membros da CoP Obeduc. A observação do desenvolvimento da tarefa serviu para gerar, durante os encontros da $\mathrm{CoP}$, discussão, reflexão e negociação de significados entre as professoras em formação e os professores com experiência docente. Com isso, a autora observou, não apenas as contribuições para a prática, mas também as reflexões feitas por estas professoras em formação sobre as atividades realizadas, a partir de suas experiências na CoP Obeduc.

Os principais resultados apontam que esse movimento de planejamento e realização de atividades, seguidos de discussão e reflexão na CoP Obeduc, contribuiu para a formação docente das futuras professoras, além de promover uma aprendizagem docente para o ensino de Matemática nos Anos Iniciais do Ensino Fundamental. A autora acredita que essas aprendizagens ocorreram devido a um conjunto de experiências vivenciadas - leituras, participação em palestras e em eventos internos e externos à CoP - pelas estudantes de Pedagogia. Além disso, a participação ativa na comunidade possibilitou a reflexão e a interlocução com os pares, o que pode ter contribuído para a aprendizagem docente, não só das estudantes de Pedagogia, como também dos professores dos Anos Iniciais que eram membros da CoP.

\section{Conclusões}

De modo geral, estudos como os de Beline (2012), Nagy (2013), Garcia (2014), Ramos (2015) e Dick (2017) apontam que a formação continuada de professores que ensinam Matemática em contextos de uma Comunidade de Prática, baseados na negociação, nas relações sociais, na reflexão das práticas, no respeito e confiança entre os membros, são uma alternativa para programas tradicionais de formação continuada fundamentados em cursos de treinamento ou de reciclagem de conhecimentos. Esse tipo tradicional de formação continuada, e até mesmo de formação inicial dos professores, fez-se presente em programas brasileiros desde meados da década de 1970 (FIORENTINI et. al, 2002) até, aproximadamente os anos 2000 quando, segundo Fiorentini e Crecci (2017), começaram a surgir grupos colaborativos de estudo que envolviam tanto professores universitários, quanto professores em formação inicial e professores da Educação Básica em processo de formação continuada.

Os estudos de Baldini (2014), Rodrigues (2016) e Boneto (2016) reforçam essa 
nova tendência de formação e, de maneira complementar, apontam que as CoP são um cenário no qual a aprendizagem compartilhada entre membros com diferentes experiências promove o desenvolvimento profissional de professores, futuros professores e pesquisadores, com ou sem o uso de tecnologias, sempre de maneira colaborativa e participativa. Os resultados desses estudos reforçam o dito nas Referências para Formação de Professores (BRASIL, 2002) de que a formação inicial, por si só, não é suficiente para que haja um desenvolvimento profissional do professor.

Em outros estudos, como Caldeira, (2010), Mendes (2013), Benites (2013), Estevam (2015), as comunidades investigadas foram criadas com características de uma Comunidade de Prática $(\mathrm{CoP})$ e sofreram algum tipo de intervenção por parte dos pesquisadores para que as ações mobilizadas a partir dessas intervenções fosse investigada. Essas ações analisadas não são definidas como colaborativas, mas como características dos elementos constituintes de uma $\mathrm{CoP}$, como engajamento mútuo e empreendimento compartilhado. As análises feitas têm foco em como estas ações permitem a aprendizagem e o desenvolvimento profissional destes professores, mas não trazem indícios de como essas aprendizagens influenciam na mobilização de novas ações, nem de como influenciam no fortalecimento de conhecimentos do conteúdo, nem de conhecimentos pedagógicos do conteúdo.

Sobre a importância desses contextos de CoP para o desenvolvimento profissional dos professores, os estudos aqui discutidos corroboram com os argumentos dos Referências para Formação de Professores (BRASIL, 2002, p. 66) de que o desenvolvimento profissional permanente do professor requer um processo contínuo de “estudo, reflexão, discussão, confrontação e experimentação coletiva". A formação de grupos com diálogos produtivos entre seus membros também é uma recomendação dos Principles and Standards for School Mathematics (NCTM, 2000), que afirma que quando os professores têm a oportunidade de trabalhar em conjunto com seus pares, refletem mais sobre suas práticas e melhoram o auxílio dado aos estudantes nos processos de aprendizagem da Matemática.

Os estudos de Barros (2016) e Silva (2017) apontaram que, além de espaços propícios para a formação de professores que ensinam Matemática, os contextos da CoP podem ser uma alternativa para estimular a reflexão da prática e gerar implicações para 
as pesquisas desenvolvidas na área e políticas públicas de aproximação entre Universidades e escolas das Educação Básica. Dessa forma, a aproximação entre estes dois segmentos da educação pode ser feita de maneira colaborativa entre os membros desses segmentos, que podem vir a constituir-se como diferentes Comunidades de Prática, uma vez que seus membros se reúnem em torno de um objetivo em comum — que é uma formação significativa e desenvolvimento profissional destes professores e a melhora do processo de ensino e aprendizagem da Matemática na Educação Básica.

Sobre a abordagem de conhecimentos docentes em Comunidades de Prática, poucas são as pesquisas que trataram esta temática específica na formação, inicial e/ou continuada, de professores que ensinam, ou ensinarão, Matemática. Os conhecimentos docentes, aqui analisados, dizem respeito aos saberes e práticas docentes num contexto de mudanças curriculares (MELO, 2010), a teoria do Conhecimento Tecnológico e Pedagógico do Conteúdo (BALDINI, 2014) e as concepções sobre o conteúdo de frações (MENEGAZZI, 2014). Entretanto, estes estudos não apresentam indícios de como os conhecimentos desses professores são capazes de promover ações colaborativas entre os membros das CoP às quais pertencem.

Observa-se que os estudos discutidos aqui, apesar de falarem sobre a colaboração na formação do professor que ensina, ou ensinará, Matemática, no âmbito das Comunidades de Prática (CoP), ou sobre conhecimentos docentes - ambos importantes para o desenvolvimento profissional do professor de Matemática - nenhum deles teve por objetivo investigar inter-relações entre estes aspectos teóricos. A partir da análise dos dados, aqui apresentados, reforça-se a importância de investigar e responder questões, tais como: O que são ações colaborativas na formação de professores? Como estas ações estão relacionadas às Comunidades de Prática nas quais estão inseridos? De que modo as ações colaborativas favorecem o fortalecimento de conhecimentos docentes no contexto de uma comunidade de prática $(\mathrm{CoP})$ ? E como os conhecimentos docentes podem proporcionar ainda mais ações colaborativas entre os membros de uma CoP? A investigação dessas questões pode trazer contribuição no que diz respeito à influência mútua de ações colaborativas e conhecimentos docentes (LIMA, 2019), para a formação, inicial e contínua, dos professores que ensinam Matemática. 


\section{Referências}

BALDINI, Loreni Aparecida Ferreira. Elementos de uma Comunidade de Prática que permitem o desenvolvimento profissional de professores e futuros professores de Matemática na utilização do software GeoGebra. 2014. 221f. Tese (Doutorado em Ensino de Ciências e Educação Matemática) — Centro de Ciências Exatas. Universidade Estadual de Londrina. Londrina.

BARROS, Márcia Alonso Tenório de. Processo de produção escrita de professores que ensinam Matemática em grupos de pesquisa. 2016. 108f. Dissertação (Mestrado em Educação Matemática) - Faculdade de Ciências Exatas e Tecnologia. Pontifícia Universidade Católica de São Paulo. São Paulo.

BELINE, Willian. Formação de professores de Matemática em Comunidades de Prática: um estudo sobre identidades. 2012. 314f. Tese (Doutorado em Ensino de Ciências e Educação Matemática) - Centro de Ciências Exatas. Universidade Estadual de Londrina. Londrina.

BENITES, Vanessa Cerignoni. Formação de Professores de Matemática: dimensões presentes na relação Pibid e Comunidade de Prática. 2013. 247f. Dissertação (Mestrado em Educação Matemática) - Instituto de Geociências e Ciências Exatas. Universidade Estadual Paulista. Rio Claro.

BONETO, Cristiane. Representações sociais acerca de uma Comunidade de Prática enquanto espaço de formação continuada. 2016. 120f. Dissertação (Mestrado em Educação Matemática) — Faculdade de Ciências Exatas e Tecnologia. Pontifícia Universidade Católica de São Paulo. São Paulo.

BRASIL. Ministério da Educação. Secretaria de Educação Fundamental. Referenciais para formação de Professores. Brasília: MEC/SEF, 1999.

BRASIL. Ministério da Educação. Secretaria de Educação Básica. Base Nacional Comum Curricular. Brasília: MEC/SEB, 2018a.

BRASIL. Ministério da Educação. Secretaria de Educação Básica. Proposta para Base Nacional Comum da Formação de professores da Educação Básica. Brasília: MEC/SEB, $2018 b$.

BRASIL. Ministério da Educação. Secretaria de Educação Fundamental. Referenciais Curriculares para a Formação de Professores. Brasília: MEC/SEF, 2002.

CALDEIRA, Janaina Soler. Um estudo sobre o pensamento algébrico em uma Comunidade de Prática de formação de professores de Matemática. 2010. 129f. Dissertação (Mestrado em Ensino de Ciências e Educação Matemática) - Centro de Ciências Exatas. Universidade Estadual de Londrina. Londrina.

COCHRAN-SMITH, Marilyn; LYTLE, Susan S. Relationships of Knowledge and Practice: Teacher Learning in Communities. Review of Research in Education, v. 24, p. 249-305, 1999. 
CYRINO, Márcia Cristina de Costa Trindade. Formação de professores que ensinam Matemática em Comunidades de Prática. In: CONGRESSO IBEROAMERICANO DE EDUCAÇÃO MATEMÁTICA, 7, Montevideo, 2013. Actas do VII CIBEM. Montevideo: SEMUR, 2013, p. 5199-5206.

DICK, Ana Paula. Aprender experimentando no contexto de uma formação continuada de professores dos Anos Iniciais. 2017. 143f. Dissertação (Mestrado em Ensino) Universidade do Vale do Taquari. Lajeado.

ESTEVAM, Everton José Goldoni. Práticas de uma comunidade de professores que ensinam matemática e o desenvolvimento Profissional em Educação Estatística. 2015. 193f. Tese (Doutorado em Ensino de Ciências e Educação Matemática) - Centro de Ciências Exatas. Universidade Estadual de Londrina. Londrina.

ESTEVAM, Everton José Goldoni; CYRINO, Márcia Cristina de Costa Trindade. Comunidades de Prática como contexto para o desenvolvimento profissional docente em Educação Estatística. Educação Matemática Pesquisa. São Paulo, v. 18, n. 3, p. 12911317, set./dez. 2016.

FIORENTINI, Dario; CRECCI, Vanessa. Metassíntese de pesquisas sobre conhecimentos/saberes na formação continuada de professores que ensinam Matemática. Zetetiké, Campinas, v. 25, n. 1, p. 164-185, jan./abr. 2017.

FIORENTINI, Dario; NACARATO, Adair Mendes; FERREIRA, Ana Cristina; LOPES, Celi Spasandin; FREITAS, Maria Teresa Meneses; MISKULIN, Rosana Giaretta Sguerra. Formação de Professores que ensinam Matemática: um balanço de 25 anos da pesquisa brasileira. Educação em Revista, Belo Horizonte, n. 36, p. 137-160, dez. 2002.

FIORENTINI, Dario; PASSOS, Cármen Lúcia Brancaglion; LIMA, Rosana Catarina Rodrigues de. (Org.). Mapeamento da pesquisa acadêmica brasileira sobre o professor que ensina Matemática: período 2001 - 2012. Campinas: FE-Unicamp, 2016.

GARCIA, Tânia Marli Rocha. Identidade professional de Professores de Matemática em uma Comunidade de Prática. 2014. 166f. Tese (Doutorado em Ensino de Ciências e Educação Matemática) - Centro de Ciências Exatas. Universidade Estadual de Londrina. Londrina.

LACERDA, Sara Miranda de. Aprender a ensinar Matemática: a participação de estudantes de Pedagogia em uma Comunidade de Prática. 2017. 210f. Tese (Doutorado em Educação Matemática) - Faculdade de Ciências Exatas e Tecnologia. Pontifícia Universidade Católica de São Paulo. São Paulo.

LIMA, Ana Paula Barbosa de. Ações colaborativas em uma comunidade de prática e o fortalecimento de conhecimentos docentes de professores de Matemática. 2019. 221f. Tese (Doutorado em Educação Matemática e Tecnológica) - Centro de Educação. Universidade Federal de Pernambuco. Recife. 
MELO, José Ronaldo. A formação do formador de professores de Matemática no contexto das mudanças curriculares. 2010. 303f. Tese (Doutorado em Educação) Faculdade de Educação. Universidade Estadual de Campinas. Campinas.

MENDES, Rosana Maria. Formação do professor que ensina Matemática, as Tecnologias de Informação e Comunicação e as Comunidades de Prática: uma relação possível. 2013. 285f. Tese (Doutorado em Educação Matemática) — Instituto de Geociências e Ciências Exatas. Universidade Estadual Paulista. Rio Claro.

MENEGAZZI, Marlene. Potencialidades e limitações de um trabalho colaborativo sobre frações na formação inicial de professores que ensinam Matemática. 2014. 221f. Dissertação (Mestrado em Ensino Matemática) - Instituto de Matemática. Universidade Federal do Rio Grande do Sul.

NAGY, Marcia Cristina. Trajetórias de aprendizagem de professoras que ensinam Matemática em uma Comunidade de Prática. 2013. 197. Tese (Doutorado em Ensino de Ciências e Educação Matemática) - Centro de Ciências Exatas. Universidade Estadual de Londrina. Londrina.

NCTM - National Council of Teachers of Mathematics. Principles and Standards for School Mathematics. Reston: NCTM, 2000.

OLIVEIRA, Laís Maria Costa Pires de. Aprendizagens no empreendimento estudo do raciocínio proporcional. 2014. 208f. Dissertação (Mestrado em Ensino de Ciências e Educação Matemática) - Centro de Ciências Exatas. Universidade Estadual de Londrina. Londrina.

PONTE, João Pedro da. Da formação do desenvolvimento profissional. In: ENCONTRO NACIONAL DE PROFESSORES DE MATEMÁTICA, 1998, Guimarães. Actas do ProfMat1998. Lisboa: APM, 1998, p. 27-44.

RAMOS, Wanusa Rodrigues. Observatório da Educação da PUC/SP e a formação de professores que ensinam Matemática em Comunidades de Prática. 2015. 130f. Dissertação (Mestrado em Educação Matemática) - Faculdade de Ciências Exatas e Tecnologia. Pontifícia Universidade Católica de São Paulo. São Paulo.

ROCHA, Márcio Roberto da. Empreendimentos de uma Comunidade de Prática de professores de Matemática na busca de aprender e ensinar frações. 2013. 133f. Dissertação (Mestrado em Ensino de Ciências e Educação Matemática) - Centro de Ciências Exatas. Universidade Estadual de Londrina. Londrina.

RODRIGUES, Márcio Urel. Potencialidades do Pibid como espaço formativo para Professores de Matemática no Brasil. 2016. Tese (Doutorado em Educação Matemática) - Instituto de Geociências e Ciências Exatas. Universidade Estadual Paulista. Rio Claro.

RODRIGUES, Márcio Urel; SILVA, Luciano Duarte; MISKULIN, Rosana Giaretta Sguerra. Conceito de Comunidade de Prática: um olhar para as pesquisas na área da educação e ensino no Brasil. REMat, São Paulo, v. 14, n. 16, p. 16-33, jan./jun. 2017. 
SILVA, Lilian Aragão. Uma análise do Observatório da Educação Matemática da Bahia à luz da Teoria Social da Aprendizagem e da Teoria dos Códigos. 2017. 167f. Tese (Doutorado em Ensino, Filosofia e História das Ciências) — Faculdade de Educação. Universidade Federal da Bahia e Universidade Estadual de Feira de Santana. Salvador.

TINTI, Douglas da Silva. Aprendizagens docentes situadas em uma Comunidade de Prática constituída a partir do Obeduc. 2016. 260f. Tese (Doutorado em Educação Matemática) — Faculdade de Ciências Exatas e Tecnologia. Pontifícia Universidade Católica de São Paulo. São Paulo.

TINTI, Douglas da Silva; MANRIQUE, Ana Lúcia. Mapeamento de pesquisas sobre aprendizagem docente em Comunidades de Prática constituídas no OBEDUC. Zetetiké, Campinas, v. 25, n 1, p. 186-203, jan./abr. 2017.

WENGER, Etienne. Communities of Practice: learning, meaning and identity. New York: Cambridge University Press. 1998.

WENGER, Etienne; McDERMOTT, Richard; SNYDER, William M. Cultivating Communities of Practice: a guide to managing knowledge. Boston: Harvard Business School Press, 2002. 